\title{
TECNOLOGIAS DA INFORMAÇÃO E DA COMUNICAÇÃO E O ENSINO DE ESPANHOL: UM OLHAR PARA O LIVRO DIDÁTICO
}

Wagner Barros Teixeira* Santiago Javier Galan ${ }^{*}$

RESUMO: O presente artigo apresenta pesquisa sobre a abordagem destinada às Tecnologias da Informação e da Comunicação (TIC) em livro didático para o ensino de Espanhol aprovado no âmbito do Programa Nacional do Livro Didático (PNLD) 2018. Trata-se de um recorte de investigação de Mestrado desenvolvida no Amazonas, baseada em pesquisa bibliográfica e documental, que tem como corpora o livro didático e o Edital de Convocação para o Processo de Inscrição e Avaliação para o PNLD 2018. Os principais teóricos que embasam a pesquisa e este artigo são AUTOR (2010, 2018), Moran, Masseto e Behrens (2012) e Guimarães e Freitas (2018). Os resultados preliminares apontam que o Edital PNLD 2018 apresenta critérios que podem ser efetivados por meio das TIC, apesar de não mencionarem explicitamente o uso desses recursos tecnológicos e, além disso, pouca variedade nas propostas didático-pedagógicas no livro didático investigado, com predominância para TIC que amparam atividades de compreensão auditiva. Constatamos, também, uma preocupante perspectiva sobre a manutenção do componente de Língua Espanhola no âmbito do PNLD.

PALAVRAS-CHAVE: Língua Espanhola; Livro didático; PNLD; TIC.

Com o passar da história, cada vez mais novas tecnologias surgem e, ao considerar os últimos anos, temos um panorama em que a sociedade vem se conectando de várias formas, a uma velocidade cada vez maior, contando com o apoio e com as vantagens que

\footnotetext{
* Doutor em Letras Neolatinas pela Universidade Federal do Rio de Janeiro (UFRJ). Professor da Universidade Federal do Amazonas (Ufam).

** Mestrando no Programa de Pós-graduação em Letras da Faculdade de Letras da UFAM. Professor no Colégio Militar de Manaus.
} 
as Tecnologias da Informação e da Comunicação (TIC) oferecem. Nesse contexto, também encontramos nosso aluno, integrado cotidianamente com as TIC e por meio delas, vivendo em um mundo em que tem acesso fácil a essas ferramentas diariamente em suas atividades.

Entretanto, na escola, mesmo com todo esse avanço tecnológico nos dias de hoje, esse aluno ainda assiste a aulas cunhadas como tradicionais, que lançam mão de estratégias típicas de uma aula expositiva e que, muitas vezes, o colocam em um contexto completamente diferente daquele com o qual está acostumado fora dos muros da escola. Infelizmente, essas aulas têm estado presentes na educação brasileira há bastante tempo, mais precisamente desde a época dos jesuítas (LOPES, 1993).

Alguém poderia questionar que a distância tecnológica entre professor e aluno não deveria acontecer em sala de aula, pois são atores sociais que interagem na mesma sociedade, em que a tecnologia perpassa o cotidiano; por isso, não seria possível afirmar a existência de choque de gerações. No entanto Lemos (2009) considera o aluno como um nativo digital, enquanto o docente, que começou a ter acesso às tecnologias em fase pós-infância, é considerado um imigrante digital. Essa diferença tem se feito grande na realidade da sala de aula brasileira, podendo explicar em parte esse distanciamento entre os atores envolvidos no processo de ensino-aprendizagem, e, ainda, a ideia de que exista um choque de gerações.

Nesse contexto, consideramos que existam alguns fatores que intervenham de maneira significativa e que possam contribuir para o (in)sucesso do processo, tais como o conhecimento das TIC por parte desses atores, a disposição e o apoio para aprender e para se capacitar sobre a questão tecnológica, a estrutura da escola no que tange à disponibilidade de TIC para uso em sala de aula, o material didático adotado - de forma especial o livro didático (LD) no que concerne à maneira como se relaciona com as TIC: por exemplo, se apresenta atividades que lancem mão de recursos tecnológicos para apoiar o processo de ensino-aprendizagem, entre outros.

Como recorte de uma pesquisa de Mestrado em andamento que se situa na área da Linguística Aplicada (LA), nosso foco neste artigo se voltará para o LD e, de forma especial, 
para um livro aprovado pelo Programa Nacional do Livro Didático (PNLD) 2018 da disciplina de Língua Espanhola (LE). Esse LD é o livro Cercanía Joven (COUTO; COIMBRA; CHAVES, 2016), que tem sido utilizado por colégios militares do Sistema Colégio Militar do Brasil (SCMB).

Nossa motivação advém de experiências docentes na Educação Básica, de forma especial no SCMB, e no Ensino Superior, como pesquisadores e formadores de professores de LE. Entre essas experiências, chamou-nos atenção e nos inquietou a questão do uso das TIC nas aulas de Espanhol das escolas da Educação Básica, principalmente, após ouvir com muita frequência o pedido dos alunos pelo uso de algumas TIC durante as aulas, pois, como a tecnologia faz parte de sua rotina diária, esperavam que também fizesse parte das práticas didáticas em sala de aula. Além disso, a inquietação se ampliou por meio de relatos dos acadêmicos do Curso de Letras que evidenciavam a ausência do uso das TIC nas aulas de Espanhol que acompanhavam em suas atividades de estágio curricular.

Além disso, justifica-se este artigo por ainda existir déficit considerável no desenvolvimento de pesquisas na área de LA sobre o LD do componente LE, diante das pesquisas voltadas para outros componentes curriculares (PARAQUETT, 2009), sendo relevante no atual contexto educacional brasileiro, especialmente após a promulgação da Lei $n^{\circ}$ 13.415 (BRASIL, 2017) que, infelizmente, confirmou uma mudança educacional que havia sido realizada de forma unilateral e impositiva por meio de Medida Provisória, perpetuando políticas de silenciamento e de apagamento linguístico no país, que determinaram o ensino de apenas uma língua estrangeira, o Inglês, fato que deixou um futuro incerto para o ensino das demais línguas no Brasil, entre as quais o Espanhol (AUTOR, 2018).

Dessa forma, considerando a inquietação mencionada, o contexto educacional brasileiro atual para o ensino de línguas e o fator LD no processo de ensino-aprendizagem, buscamos responder à seguinte pergunta: de que formas as TIC estão presentes no LD para ensino de Espanhol aprovado pelo PNLD - Edição 2018?

Para seguir esse caminho e alcançar o objetivo proposto, baseamos a investigação em pesquisa bibliográfica e documental, tendo como corpora o Edital de Convocação para 
o PNLD 2018 de LEM e o livro didático Cercanía Joven (op. Cit.) - volume 1 aprovado pelo referido Programa.

Com vistas a subsidiar nossa análise, a seguir, apresentamos alguns conceitos sobre tecnologia e sobre as TIC no processo de ensino.

\section{As TIC e a Educação}

Para entender o conceito de TIC, apresentamos algumas concepções. Não se pode afirmar que seja uma palavra polissêmica, pois, como veremos, as diversas definições têm uma relação entre conceito, prática e objetivo.

Para Miranda (2007), TIC é a união das tecnologias telecomunicativas com a informática e, especialmente, com a Internet, e, quando usadas com objetivos educacionais, denominam-se Tecnologias Educativas.

Imbérnon (2010) destaca que TIC são um conjunto de recursos tecnológicos que, quando integrados, podem promover a automação e/ou a comunicação de diferentes tipos de processos existentes em diversas áreas como a de negócios, a do ensino e a da pesquisa científica.

Em outra definição se afirma que

É inevitável a associação do termo tecnologia de informação com informática, rede de computadores, Internet, multimídia, banco de dados e demais recursos oferecidos por essa ferramenta. Todas as outras tecnologias (telefone, rádio, TV, vídeo e áudio), que antes eram utilizadas em separado, hoje foram integradas por meio do computador e seus periféricos, como câmeras de vídeo, impressoras, conexão à Internet, leitores e gravadores de discos óticos, sistemas de áudio, estações de rádio e TV acessíveis via Internet. (VEEM; VRAKKING, 2009)

Para Moran, Masseto e Behrens (2012), TIC é a área que utiliza ferramentas tecnológicas com os objetivos de facilitar a comunicação e de atingir uma meta comum. Se- 
melhante conceito define as TIC como a área que faz uso da computação como instrumento para produzir, transmitir, armazenar, acender e utilizar diversas informações, “[...] auxiliando o utilizador a alcançar um determinado objetivo.” (VIEIRA, 2011, p. 16)

Menções como união de tecnologias, conjunto de recursos tecnológicos, além de ferramentas e de instrumentos tecnológicos, encontradas nos conceitos supracitados, demonstram que, apesar de o conceito ser amplo e complexo, há uma referência às diversas atividades realizadas com o apoio das TIC, no intuito de alcançar determinado objetivo no caso específico das TIC na educação, o de auxiliar o processo de ensino-aprendizagem, ao qual o LD está vinculado.

Nessa esteira, são cada vez mais variadas as TIC presentes no cotidiano. Hoje em dia, além da famosa televisão, temos a nossa disposição tablets, celulares, computadores pessoais e portáteis, telas digitais e interativas, câmeras para computador ou Webcams, suportes para guardar e portar dados como HD e cartões de memória, tecnologias de acesso remoto como Wi-fi e Bluetooth, tecnologias digitais de captação e de tratamento de imagens e de sons como Vimeo e Youtube, diversos tipos de aplicativos, e muito mais, cada vez mais e mais.

No que concerne à educação e, de forma especial, no que tange o processo de ensino-aprendizagem de idiomas, segundo AUTORES (2012), o uso das TIC com objetivos didáticos teve início durante a segunda guerra mundial, quando os Estados Unidos usaram essas ferramentas para conseguir que seus soldados aprendessem no menor tempo possível o idioma do inimigo. A partir de então, o ensino de idiomas vem sendo pautado por metodologias que utilizam recursos tecnológicos variados, tais como os mencionados anteriormente. Entretanto, desde o surgimento do computador e da Internet, aconteceu uma verdadeira revolução na sociedade em geral, e, por conseguinte, no processo de ensino-aprendizagem.

O professor contemporâneo enfrenta diversos desafios em sala de aula. Dentre eles está a busca por alternativas para diminuir a distância que o separa de seu aluno em relação ao uso das tecnologias em sala de aula, pois o uso das TIC é uma realidade e prática muito 
comum no cotidiano do discente; entretanto, na aula, muitos docentes fazem o caminho inverso e, por diversos motivos, não aproveitam ou fazem pouco uso dessas ferramentas.

No decurso de nossas vidas acadêmicas e profissionais, como já mencionado, entre nossas inquietações está a preocupação por inserir em nossas práticas pedagógicas o uso das TIC, pois a tecnologia faz parte do cotidiano do aluno, e, por tanto, entendemos que a escola não pode estar desvinculada da realidade cotidiana do discente. Essa preocupação é também encontrada na Base Nacional Comum Curricular (BNCC) (BRASIL, 2018), que recomenda ao professor "[...] selecionar, produzir, aplicar e avaliar recursos didáticos e tecnológicos para apoiar o processo de ensinar e aprender”. (BRASIL, 2018, p. 17)

Está constatado que, geralmente, há uma distância entre o mundo em que nosso aluno vive fora de sala de aula e a realidade que ele encontra dentro dela. Afirma-se que o discurso da escola está longe da realidade do discente, se comparado ao discurso da televisão, por exemplo, que educa por meio do sensorial e do afetivo (MORAN; MASSETO; BEHRENS, 2001), ou ao discurso de outras TIC mais recentes. Estar em um ambiente em que o aluno interaja com instrumentos em atividades que façam parte de seu cotidiano é uma forma de aproveitar para o sensibilizar e o envolver em determinado assunto, e o LD não pode ficar alheio a essa situação.

Estudos diversos apontam várias razões pelas quais o uso da tecnologia fica limitado em sala de aula. Entre elas está o fator tempo, tanto para planejar, como para preparar e para aplicar alguma estratégia de ensino com o apoio das TIC (AUTOR, 2010; AUTOR, 2010; AUTORES, 2012), além da falta de preparo dos professores para lidar com essas tecnologias (CARDOSO, 2015). Porém, tanto a questão do tempo como a da falta de capacitação não são os únicos fatores que limitam o uso das TIC em sala de aula, havendo outros, como a falta de estrutura das escolas no que concerne à disponibilidade de recursos tecnológicos para uso por professores e alunos, a falta de efetivas políticas de incentivo à formação continuada, e a falta de valorização dessas ferramentas em políticas educacionais materializadas em propostas curriculares, em programas de capacitação docente, e, ainda, em programas de fornecimento de recursos para as escolas, como o PNLD. 
Tomando como base nosso recorte voltado para o LD de LE, sobre essa questão, a seguir, apresentamos um resumo.

\section{Breve panorama sobre o LD de Espanhol no PNLD}

O Programa Nacional do Livro Didático no Brasil tem sua criação em 1985, em substituição ao Programa do Livro Didático para o Ensino Fundamental (PLIDEF), fato que, segundo AUTOR (2018), favoreceu a melhoria nos processos de avaliação, seleção e distribuição dos livros didáticos, principalmente com a inclusão e a participação de professores da Educação Básica, do Ensino Superior e de pesquisadores no processo.

Ao considerar a importância do LD, Soares (2007, p. 17) afirma que é um produto que tem por objetivo “[...] satisfazer expectativas de venda, de veiculação de valores” e, também, é um “[...] instrumento de formação de condutas pedagógicas.” Para Batista (2009, p. 41) o LD é “[...] empregado pela escola, para o desenvolvimento de um processo de ensino ou de formação."

No que concerne ao LD de LE no âmbito do PNLD, o primeiro edital de convocação para inscrição no processo de avaliação e de seleção de coleções didáticas para o PNLD data de 2011, sendo destinado às Séries Finais do Ensino Fundamental e, posteriormente, em 2012, ao Ensino Médio. Em ambos editais, a LE aparece junto com a Língua Inglesa (LI), fazendo parte do componente Línguas Estrangeiras Modernas (LEM). O mesmo ocorreu em 2014, em edital para o Ensino Fundamental, e em 2015, em edital para o Ensino Médio.

Em 2018, abriu-se novo edital para a seleção de livros didáticos para o PNLD voltados para o Ensino Médio, senso a LE parte dos componentes curriculares no edital. Os três livros aprovados foram Cercanía Joven (op. Cit.), Sentidos en Lengua Española (COSTA; FREITAS, 2016), Confluencias (DIB et al., 2016).

É importante ressaltar que no edital de chamada do PNLD de 2018 ocorreu uma alteração significativa: a separação do componente curricular LEM em duas áreas: LEM (Inglês) e LEM (Espanhol), o que, segundo AUTOR (op. Cit.) significou o enfraquecimento 
dessa área, em especial no que concerne ao Espanhol, separado do Inglês, haja vista que, nos editais subsequentes, a LE não foi mais considerada, refletindo as políticas brasileiras de silenciamento linguístico que infelizmente seguem sendo impostas em nosso país.

Após esse breve panorama, a seguir, passamos à análise dos documentos que compõem os corpora da pesquisa que originou este artigo.

\section{As TIC no Edital do PNLD 2018}

Garrido (2016) conceitua o edital de convocação do PNLD como um instrumento utilizado pelo Estado para definir normas de inscrição, condutas de participação, documentação necessária, etapas de avaliação da obra, aquisição e entrega. Segundo AUTOR (2018), esse processo teve início no Brasil em 1996 com os livros didáticos referentes aos quatro primeiros anos do Ensino Fundamental, para, posteriormente, em 2011, acontecer a primeira chamada do PNLD contemplando o componente de LEM do Ensino Fundamental e, um ano depois, publicar-se o primeiro edital de convocação do PNLD contemplando o componente de LEM para o Ensino Médio.

Visando a alcançar o objetivo traçado, focamos na observação e na análise dos critérios didático-pedagógicos relacionados às TIC no Edital do PNLD 2018, presentes e separados em critérios comuns a todas as áreas, em critérios e em princípios na área de Linguagens e em critérios e em princípios no componente curricular LEM (Espanhol).

Como este artigo se baseia em uma pesquisa de Mestrado em andamento que analisa a presença das TIC em uma coleção aprovada pelo PNLD 2018, analisamos, a seguir, o edital do referido programa, tendo em conta as exigências e os critérios que devem ser cumpridos pelas editoras, mais especificamente os que concernem à presença das TIC nos LD do componente LEM (Espanhol).

Nesse sentido, na página 33, em relação à legislação, às diretrizes e às normas que regem o Ensino Médio, no que concerne aos critérios eliminatórios comuns a todas as áreas, o documento analisado afirma que 
[...] serão excluídas as obras didáticas que não obedecerem aos seguintes estatutos:

b.7. Lei $n^{\circ} 13.006 / 2014$ - obriga a exibição de filmes de produção nacional nas escolas de educação básica

[...]. (BRASIL, 2015)

Ao pontuar a importância do trabalho com filmes, entendemos que o Edital amarra a questão das TIC, uma vez que são recursos utilizados para apoiar a exibição cinematográfica. Assim, espera-se que as obras de alguma forma considerem essa questão.

Além disso, na página 36, nos critérios eliminatórios e princípios específicos da área de Linguagens, o documento afirma que

[...] a área de Linguagens é um espaço escolar especialmente propício para:

$[\cdots]$

b. a organização didática de um conjunto bastante diversificado de práticas sociais - verbais, musicais, visuais e corporais - de expressão, comunicação e interação social;

[...]. (BRASIL, 2015)

Mais uma vez, o Edital evidencia a importância das TIC, pois atrela à organização didática diferentes práticas sociais, entre as quais as musicais, que necessitam do suporte de recursos tecnológicos para sua efetivação. Assim, espera-se que as obras também contemplem essa questão.

Outro exemplo vemos no item 3.1.2, que versa sobre os princípios e objetivos gerais para o Componente Curricular LEM no Ensino Médio, exigindo o compromisso de propostas de aprendizagem que

$[\cdots]$

b. favoreçam o acesso a múltiplas linguagens e gêneros de discurso (orais, escritos, visuais, híbridos) produzidos em distintas épocas e espaços;

$[\ldots]$

d. deem acesso a situações nas quais a fala e a escrita possam ser aprimoradas a partir da compreensão de suas condições de produção e circulação, bem como de seus propósitos sociais. (BRASIL, 2015, p. 39) 
Ao considerar múltiplas linguagens e diferentes gêneros de discurso orais, escritos, visuais e híbridos, o Edital abre espaço para as TIC, que servem de suporte para algumas dessas linguagens e alguns desses gêneros. Assim, espera-se que as obras apresentem propostas que se relacionem com o uso das TIC para apoiar o acesso a essas linguagens e a esses gêneros múltiplos.

Outro importante exemplo encontramos no item que trata especificamente dos critérios eliminatórios para o componente curricular LEM (Espanhol e Inglês), ao observar se a obra

$[\ldots]$

c. contempla variedade de gêneros do discurso, concretizados por meio de linguagem verbal, não verbal ou verbo-visual, caracterizadora de diferentes formas de expressão na língua estrangeira e na língua nacional;

$[\ldots]$

k. promove atividades de fala e escuta que contemplem variedade de gêneros de discurso característicos de oralidade;

1. apresenta atividades que permitam o acesso a diferentes pronúncias e prosódias, em situação de compreensão oral;

[...]. (BRASIL, 2015, p. 39)

Por meio desse item, o Edital prevê critérios que dependem das TIC para se efetivarem no LD, uma vez que muitas atividades que promovem a oralidade se apoiam no uso de recursos tecnológicos audiovisuais e digitais, principalmente no que concerne a facilitar o acesso a diferentes pronúncias e prosódias em situação de compreensão oral.

Pelo exposto, apesar de não mencionarem o termo TIC e de não especificarem os recursos que possam ser usados para apoiar as atividades previstas, os fragmentos do Edital destacados são exemplos que evidenciam a necessidade do uso das TIC nas aulas de Espanhol e, portanto, esses recursos tecnológicos devem estar previstos no LD.

Com vistas a completar nossa análise neste artigo, indo ao encontro do objetivo proposto, a seguir, direcionamos nosso olhar para o volume 1 da coleção Cercanía Joven (op. Cit.), LD aprovado pelo PND 2018, outro dos corpora de nossa investigação. 


\section{As TIC no LD Cercanía Joven}

Como este artigo se baseia em uma pesquisa de Mestrado em andamento, foi feito um recorte do volume um (1) do livro didático de Espanhol aprovado pelo PNLD de 2018 Cercania Joven (op. Cit.). Por conseguinte, nosso foco recai sobre os capítulos um (1), dois (2), três (3), quatro (4), cinco (5) e seis (6) do referido volume do LD.

Os princípios e critérios exigidos no Edital relacionados às TIC estão presentes nas partes que tratam sobre o Ensino Médio de forma geral, sobre a área de Linguagens e sobre o componente curricular LEM. Conforme visto anteriormente, apesar de não mencionarem explicitamente o uso das TIC, os critérios que permitem ao professor recorrer ao apoio desses recursos tecnológicos são aqueles que tratam da exibição didática de filmes, das múltiplas linguagens - em especial a musical, dos gêneros discursivos, das situações de fala e de escrita, e das diferentes pronúncias e prosódias na língua estudada.

Retomando o foco aos critérios comuns a todas as áreas, no item 2.1.1, que trata da legislação, focando as diretrizes e as normas oficiais relativas ao Ensino Médio, há uma exigência no subitem b.7., em consonância com a Lei n ${ }^{\circ}$ 13.006/2014 (BRASIL, 2014), da obrigação da exibição de filmes de produção nacional nas escolas de Educação Básica.

Analisando os seis capítulos do LD foco de nosso pesquisa, encontramos uma única menção a uma obra fílmica brasileira, na pág. 127, quando é solicitada a leitura de sinopses de alguns filmes, dentre as quais a do filme brasileiro $O$ ano em que meus pais saíram de férias (HAMBURGUER, 2006), e, em seguida, recomenda-se que se organize e se realize uma amostra de cinema com alguns dos filmes sugeridos, dentre os quais o filme brasileiro.

Em relação aos gêneros do discurso, exigidos nos princípios e critérios específicos para o componente LEM, o LD é bem explícito ao mencionar no início e no meio de cada capítulo o gênero discursivo que será abordado. Os objetivos estão relacionados com as habilidades discursivas, como visto no seguinte quadro. 


\begin{tabular}{|c|l|l|}
\hline Capítulos & Objetivos/Habilidade & Gênero discursivo \\
\hline 1 & $\begin{array}{l}\text { Compreensão auditiva } \\
\text { Expressão escrita }\end{array}$ & $\begin{array}{l}\text { Letra de canção } \\
\text { Postal }\end{array}$ \\
\hline 2 & $\begin{array}{l}\text { Compreensão leitora } \\
\text { Expressão oral }\end{array}$ & $\begin{array}{l}\text { Documentos de identificação } \\
\text { Entrevista }\end{array}$ \\
\hline 3 & $\begin{array}{l}\text { Compreensão leitora } \\
\text { Expressão escrita }\end{array}$ & $\begin{array}{l}\text { Entrevista } \\
\text { Entrevista }\end{array}$ \\
\hline 4 & $\begin{array}{l}\text { Compreensão auditiva } \\
\text { Expressão oral }\end{array}$ & $\begin{array}{l}\text { Entrevista } \\
\text { Convite }\end{array}$ \\
\hline \multirow{2}{*}{5} & $\begin{array}{l}\text { Compreensão leitora } \\
\text { Expressão escrita }\end{array}$ & $\begin{array}{l}\text { Discurso político } \\
\text { Infográfico }\end{array}$ \\
\hline \multirow{2}{*}{6} & $\begin{array}{l}\text { Compreensão auditiva } \\
\text { Expressão oral }\end{array}$ & $\begin{array}{l}\text { Convite e Notícia } \\
\text { Debate }\end{array}$ \\
\hline
\end{tabular}

Fonte: Elaborado pelos autores.

Com base no quadro, a seguir, analisamos os capítulos, os objetivos e os gêneros discursivos que são abordados com o suporte das TIC no LD.

No capítulo um, as TIC estão presentes por meio de atividades de compreensão auditiva relacionadas à canção 300 kilos (COYOTES, 2005) e em atividades de repetição do alfabeto da língua espanhola.

No capítulo dois, na primeira parte, há predominância pelas atividades da habilidade leitora. As TIC aparecem na atividade de compreensão auditiva da canção Visa para un sueño (GUERRA, 1989) e em atividades de repetição de numerais. No mesmo capítulo, por meio do gênero discursivo entrevista, se objetiva linguisticamente a habilidade da expressão oral. Assim, as TIC vão reaparecer apenas na atividade de compreensão auditiva referente às canções Guantanamera (MARTÍ, 1963) e Aquarela do Brasil (BARROSO, 1939).

No capítulo três, o gênero discursivo volta a ser a entrevista e os principais objetivos linguísticos são as habilidades da compreensão leitora e de expressão escrita. Apresentamse entrevistas escritas e atividades com o enfoque de práticas escritas, sem o envolvimento das TIC.

No capítulo quatro, volta a se repetir o gênero discursivo entrevista, e é abordado o gênero discursivo convite, com os quais se objetiva alcançar as habilidades linguísticas da 
compreensão auditiva e da expressão oral. As TIC se fazem presentes em três atividades de compreensão auditiva, com destaque para uma dessas práticas em que se ressalvam as diferenças fonéticas do LL, indo ao encontro do subitem do Edital voltado aos critérios específicos para o componente de LEM, que observa se a obra apresenta atividades que permitam o acesso a diferentes pronúncias e prosódias, em situação de compreensão oral.

No quinto capítulo, os gêneros são o discurso político e o infográfico e objetivam o desenvolvimento das habilidades de compreensão leitora e de expressão escrita, é uma das formas de expressão na língua nacional e língua estrangeira, sendo uma das exigências específicas de um subitem no edital do PNLD LEM 2018. A única atividade do capítulo que lança mão do uso das TIC é a de compreensão auditiva da canção Yo pisaré las calles nuevamente (MILANÉS, 1976).

No sexto capítulo do LD, os gêneros do discurso são o convite, a notícia e o debate, e os objetivos estão relacionados à compreensão auditiva e à expressão oral. Há três atividades em que as TIC estão presentes: a primeira uma atividade de compreensão auditiva sobre uma notícia e um convite, a segunda é uma atividade referente a algumas diferenças fonéticas da língua espanhola, e a terceira apresenta orientação para realização de uma atividade de apresentação de filmes e de debates sobre essas produções.

Ainda no capítulo seis, verificamos a recomendação de se escolher um dos cinco filmes sugeridos, a fim de assistir e de promover debate em sala de aula, indo ao encontro do item que se baseia em legislação que determina a abordagem de filmes nacionais no processo de ensino-aprendizagem em sala de aula.

Ao analisar de forma geral os seis capítulos supramencionados, observamos que o uso das TIC no LD predomina por meio de atividades de compreensão auditiva, principalmente no que concerne a canções e a estudos sobre diferenças fonéticas da língua espanhola. No que concerne ao CD de áudio que acompanha o LD, contém dezenove faixas, das quais sete dão suporte a atividades relacionadas a canções, oito a atividades de prática 
de pronúncia, e quatro a outros tipos de atividades de compreensão auditiva como entrevistas, narrações etc. Dessa forma, fica evidenciada a importância dessa tecnologia como apoio ao LD de LE no processo de ensino-aprendizagem do idioma.

Cabe ressaltar também o número de atividades relacionadas a canções, contemplando o item do Edital específico para a área de Linguagens, que se refere à organização didática do LD considerando as diferentes práticas sociais.

Além disso, verificamos que os seis capítulos analisados do volume 1 do LD Cercania Joven (op. Cit.) apresentem indicação de vinte e nove (29) sites digitais como forma de reforçar o estudado em sala de aula, abrindo mais um espaço para o uso das TIC.

Feitas as análises, a seguir, apresentamos algumas considerações finais.

\section{Mais algumas considerações...}

Para tecer essas considerações, retomamos a pergunta que fizemos no início do texto: de que formas as TIC estão presentes no LD para ensino de Espanhol aprovado pelo PNLD - Edição 2018? Uma constatação inquietante é o fato de que no Edital de 2018 a menção específica e direta às TIC é tímida, resumindo-se praticamente aos CD de áudio e menções diluídas sobre esse conjunto de recursos tecnológicos nos critérios do Edital. Cremos ser importante ressaltar que em editais anteriores - 2014, 2015 e 2017 - havia mais espaço para as TIC, representadas, por exemplo, pelos objetos educacionais digitais, o que foi considerado um avanço na proposta para os LD pelo PNLD (GALVÃO; RUAS, 2018).

Em relação à abordagem das TIC no LD Cercanía Joven (op. Cit.) analisado, percebemos a presença de atividades que necessitam do suporte dessas tecnologias para sua realização, sendo grande parte delas destinada à prática de aspectos fonéticos na língua estudada, e as demais voltadas para a abordagem de gêneros discursivos orais, com predominância para a entrevista.

Percebemos ainda predominância de atividades voltadas à abordagem de gêneros discursivos escritos e uma maior variedade desses gêneros (seis categorias diferentes), em comparação com o trabalho com os gêneros orais (apenas três categorias diferentes). 
Outra observação que nos parece importante fazer é a de que o LD analisado indica a consulta de vários sites digitais, como forma de apoio, sendo muitas das atividades propostas nesses sites específicas para serem realizadas com o apoio das TIC. Dessa forma, surgem novos questionamentos: Por que não usar essas sugestões em sala de aula? Seria mais fácil indicar a consulta a esses sites e a realização dessas atividades em casa, ou seja, para que o aluno as realize fora do ambiente da sala de aula? Seria um indicativo de que o trabalho com as TIC ainda é visto como complementar, secundário e acessório, e, assim, poderia ser deixado de lado pelo professor? São questionamentos importantes, que vão ao encontro das inquietações que geraram a pesquisa que originou este artigo, elucidando que a realidade da sala de aula no que concerne ao uso das TIC difere da realidade fora da escola. Essa é uma questão que necessita de maior investigação e, por isso, deixamos aqui como encaminhamento para que novas pesquisas possam se aventurar sobre a temática.

Ainda na esteira dos encaminhamentos, entendemos ser relevante para o processo de ensino-aprendizagem de um idioma que o professor possa refletir sobre o papel das TIC nesse processo e, principalmente, sobre como esses recursos tecnológicos podem contribuir para sua prática em sala de aula. Para tanto, parece-nos ser necessário que as políticas públicas considerem essa questão e que possam preencher as lacunas que historicamente têm sido abertas na educação brasileira, promovendo formações inicial e continuada adequadas, apoiando a participação de docentes em capacitações sobre temas variados, entre os quais a temática do uso das TIC em sala de aula, e que forneçam condições para que o professor possa ter acesso em sua escola a essas tecnologias, seja via recursos físicos presentes no inventário da escola, seja via atividades exploradas no LD adotado, que, a nosso ver, deve ser uma ferramenta que colabore para esse processo de formação continuada, apoiada por outras ferramentas que componham um conjunto tecnológico a serviço do processo educacional em sala de aula. Dessa forma, será possível diminuir a diferença entre as realidades dentro e fora da sala de aula, assim como evitar o tão mencionado 'choque de gerações' entre professor e alunos, reforçando a inclusão e a integração das TIC no processo de ensino-aprendizagem e sua incorporação pelos diferentes atores nesse processo. 
Antes de terminar o texto, gostaríamos ainda de destacar outro aspecto que nos chamou atenção durante as investigações realizadas, relacionado às políticas públicas supramencionadas. Trata-se da exclusão do componente LEM (Espanhol) do PNLD. Essa situação se confirmou no Edital para o Ensino Fundamental no PNLD 2020, indo ao encontro de previsões de pesquisadores como AUTOR (2018) e Freitas e Guimarães (2018), que se preocuparam com a possível retirada do componente.

Entendemos ser mais um exemplo das políticas de silenciamento que têm sido implementadas historicamente no Brasil e que, infelizmente, cerceiam os direitos do aluno de ter acesso a novas culturas, de se (re)conhecer a partir do outro, e de ampliar seus horizontes. Diante desse quadro, faz-se necessária e urgente a manutenção de ações glotopolíticas de resistência que garantam a pluralidade, o acesso a bens culturais como as línguas estrangeiras e, principalmente, a formação plena do cidadão no Brasil, começando pela sala de aula.

\section{TECNOLOGÍAS DE INFORMACIÓN Y COMUNICACIÓN Y ENSEÑANZA DE ESPAÑOL: UNA MIRADA AL LIBRO DIDÁCTICO}

RESUMEN: Este artículo presenta investigación sobre el abordaje de las Tecnologías de la Información y de la Comunicación (TIC) en un libro didáctico para la enseñanza del Español aprobado por el Programa Nacional do Livro Didático (PNLD) 2018. Se trata de parte de una investigación de Maestría desarrollada en el Amazonas, basada en pesquisa bibliográfica y documental, que tiene como corpora el libro didáctico y el Edital de Convocação para o Processo de Inscrição e Avaliação para o PNLD 2018. Los principales investigadores que les dan soporte a esta investigación y a este artículo son AUTOR (2010, 2018), Moran, Masseto y Behrens (2012) y Guimarães y Freitas (2018). Los resultados preliminares señalan que el Edital PNLD 2018 presenta criterios que se pueden efectivar por medio de las TIC, aunque no mencionen explícitamente el uso de esos recursos tecnológicos y, además, que hay poca variedad en las propuestas didáctico-pedagógicas en el libro didáctico investigado, predominando TIC que amparan actividades de comprensión auditiva. Constatamos, también, preocupante perspectiva sobre la manutención del componente de Lengua Española en el PNLD.

PALABRAS-CLAVE: Lengua Española; Libro didáctico; PNLD; TIC. 


\section{REFERÊNCIAS}

BARROSO, A. Aquarela do Brasil. Brasil, 1939. Disponível em: http//www.arybarroso.com.br/sec_musica_letra.php?language=pt_BR\&rid=34. Acesso em: 30 nov. 2015.

BRASIL, Lei $N^{\circ}$ 13.006, de 26 de junho de 2014. Disponível em: http:/ /www.planalto.gov.br/ccivil_03/_Ato2011-2014/2014/Lei/L13006.htm.

Lei $N^{0} 13.415$, de 16 de fevereiro de 2017. Disponível em: https://presrepublica.jusbrasil.com.br/legislacao/431644888/lei-13415-17. Acesso em: 30 ago. 2019.

BRASIL, Ministério da Educação. Base Nacional Comum Curricular - BNCC $3^{\mathrm{a}}$ versão. Brasília, DF, 2018.

Edital de convocação para o processo de inscrição e avaliação de obras didáticas para o Programa Nacional do Livro Didático PNLD 2018. Secretária de Educação Básica - SEB Fundo Nacional de Desenvolvimento da Educação. Brasília, DF: Ministério da Educação, Secretaria de Educação Básica, 2015. Disponível em: < http://www.fnde.gov.br/programas/programas-do-livro/consultas/editais-programas-livro/item/7932-pnld-2018>. Acesso em: 13 dez. 2018.

CARDOSO, A. C. Formação inicial de professones de inglês para o uso das tecnologias digitais: uma pesquisaação no contexto do estágio supervisionado. Tese (Doutorado em Linguística Aplicada) - Faculdade de Letras, Universidade Federal do Rio de Janeiro. Rio de janeiro, 2015.

COSTA, E. G. de M.; FREITAS, L. M. A. Sentidos en lengua española. 1. ed. Rio de Janeiro: Richmond, 2016.

COUTO, A. L.; COIMBRA, L.; CHAVES, L. S. Cercanía Joven. 2. ed. São Paulo: SM, 2016.

COYOTES, Los 300 Kilos. España, 2005. Disponível em: < http:/ / www.coveralia.com/letras/lo-coyotes-300-kilos-la-edad-de-oro-del-pop-español.php>. Acesso em: 03 nov. 2015.

DIB V. A. et al. Confluencia. 1. ed. São Paulo: Moderna, 2016.

AUTOR. Aula de espanbol na universidade: uma reflexão sobre a aula expositiva num curso de Letras Língua Espanhola em Manaus. 2010. Artigo de TCC de Pós-Graduação (Metodologia do Ensino Superior) Escola Superior Batista do Amazonas, Manaus 2010.

AUTORES. Barreras al uso de las Tecnologías de la Información y de la Comunicación en la enseñanza de Lenguas. (2012) In: Revista Pesquisas em discurso pedagógico. Disponível em: < https://www.maxwell.vrac.puc-rio.br/20009/20009.PDF>. Acesso em: 10 de jul. 2018 .

GARRIDO, M. C. M. História que os livros didáticos contam depois do PNLD: História da África e dos Afro-brasileiros por intermédio dos editais de convocação do PNLD. In: Histórias e Perspectivas, Uberlândia (54): 239-268, jan./jun. 2016. 
GUERRA, J. L. Visa para un sueño. República Dominicana, 1989. Disponível em: <https://www.youtube.com/watch?v=dF71wn-MPnA>. Acesso em: 30 ago. 2019.

GUIMARÃES, A; FREITAS, L. Memória do livro didático de espanhol no Brasil: um panorama. In: BARROS, C. et al. (Orgs.) O livro didático de espanhol na escola brasileira. Campinas, SP: Pontes Editores, 2018. p. 15-33.

HAMBURGUER, C. O ano em que meus pais saíram de férias. Brasil, 2006. Disponível em: <https://www.youtube.com/watch?v=yplwrQIWgIw. Acesso em: 30 nov. 2019.

IMBERNÓN, F. Formação docente e profissional: formar-se para a mudança e a incerteza. 7 . Ed. São Paulo: Cortez, 2010.

LEMOS, S. Nativos digitais $x$ aprendizagens: um desafio para a escola. Senac, Rio de Janeiro, v. 35, n.3, set./dez. 2009.

LOPES, A. O. Aula Expositiva: superando o tradicional. In: VEIGA, I. P. A. (Org.) Técnicas de Ensino: por que não? 2. ed. Papirus, 1993.

MARTÍ, J. Guantanamera. Cuba, 1963. Disponível em: http//letras.mus.br/raices-de-america/783788/. Acesso em: 12 abr. 2016.

MILANÉS, Pablo. Yo pisaré las calles nuevamente. Chile, 1976. Disponível em: https://www.vagalume.com.br/pablo-milanes/yo-pisare-las-calles-nuevamente.html. Acesso em: 30 ago. 2019.

MIRANDA, G. L. Limites e possibilidades das TIC na educação. In: Sísifo: Revista de Ciências da Educação, 2007.

MORAN, J. M.; MASSETO, M. T.; BEHRENS, M. Novas Tecnologias e Mediação Pedagógica. 4. ed. Campinas: Papirus, 2001.

. Novas tecnologias e mediações pedagógicas. Campinas, SP. Papirus, 2012.

PARAQUETT, M. O papel que cumprimos os professores de espanhol como língua estrangeira (E/ELE) no Brasil. In: Cadernos de Letras da UFF, v.38, p. 123-138, 2009.

AUTOR. Panorama (Gloto)político sobre o livro didático e o ensino de espanhol no Brasil. In: BARROS, C. et al. (Orgs.) O livro didático de espanhol na escola brasileira. Campinas, SP: Pontes Editores, 2018. p. 331-342.

- O uso das Tecnologias de Informação e da Comunicação em Aulas de Lingua Materna e Estrangeira. 2010. Monografia (Especialização em Educação Tecnológica). Centro Federal de Educação Tecnológica Celso Suckow da Fonseca, Rio de Janeiro, 2010.

VEEM, W.; VRAKKING, B. Homo Zappiens: educando na era digital. Porto Alegre: Artmed, 2009. 
VIEIRA, R. S. O papel das tecnologias da informação e comunicação na educação: um estudo sobre a percepção do professor/aluno. Formoso - BA: Universidade Federal do Vale do São Francisco (UNIVASF), 2011. v. 10.

Recebido em: 09/03/2019.

Aprovado em: 12/01/2020. 